TRANS · núm. I7 2013

DOSSIER $\cdot 13-34$
El doblaje, junto a la subtitulación, es una de las modalidades de traducción audiovisual más extendidas y practicadas por todo el mundo. Sus orígenes se remontan al final de la década de 1920, dada la necesidad de traducir los nuevos filmes sonoros a otras lenguas y culturas. Este artículo sitúa al doblaje en el universo de la traducción audiovisual, echa la vista atrás para rescatar los orígenes de la investigación sobre traducción para el doblaje, y ofrece un resumen de los primeros estudios teóricos y aquellos realizados bajo un prisma más profesional. Tras explicar estos primeros estudios, el artículo pasa a comparar los estudios centrados en el texto origen, con los centrados en el texto meta bajo el paradigma descriptivista. Finalmente, el artículo propone una serie de avenidas de investigación en el campo de la traducción para el doblaje que todavía siguen estando casi vírgenes para la comunidad científica. En cada una de las secciones, se incluyen los conceptos y nociones básicas que han caracterizado cada paradigma, como las nociones de restricciones, dubbese o normas de traducción para el doblaje. El artículo también presenta nuevos géneros audiovisuales y nuevas combinaciones de modalidades de traducción audiovisual que progresivamente están empezando a cambiar el mercado del doblaje.

PalABRAS ClaVE: doblaje, investigación, restricciones, dubbese, normas, descriptivismo, ideología, profesión

\title{
Panorámica de la investigación en traducción para el doblaje
}

\section{Research in Translation for Dubbing: An Overview}

Dubbing, together with subtitling, is one of the most widespread types of audiovisual translation. Its origins can be traced back to the late twenties, with the need to transfer the new sound films to other languages and cultures. This article places dubbing in the world of audiovisual translation, reviews the origins of research on dubbing, and offers an overview of the first theoretical and professional approaches to this audiovisual translation mode. The paper then sets out to compare research approaches centred on the problems posed by the source text to descriptive approaches focused on the target text. It concludes by showing research avenues which are still unexplored and call for urgent attention among the academic community. Each section explores basic concepts which have proved to be useful to audiovisual translation theory, such as the notion of translation constraints, dubbese and

Frederic Chaume dubbing norms. The article also presents new genres and new combinations Universitat Jaume I of audiovisual translation modes that are progressively changing the dubbing industry.

KEY WORDS: dubbing, research, constraints, dubbese, norms, descriptivism, ideology, profession 


\section{LA TRADUCCIÓN AUDIOVISUAL Y EL DOBLAJE ${ }^{\text {I }}$}

La traducción audiovisual (TAV) es la denose refieren a las transferencias semióticas, interlingüísticas e intralingüísticas entre textos audiovisuales, tanto a las más consolidadas, como el doblaje y la subtitulación, como a las más novedosas, como el rehablado o la audiosubtitulación, por ejemplo. El término traducción audiovisual, como concepto académico, va penetrando lentamente en los círculos profesionales dedicados a la postproducción de la imagen y el sonido, donde esta denominación no era utilizada hasta hace muy poco — aunque lo eran las diferentes prácticas en sí, sobre todo las tradicionales. Doblaje y subtitulación, pero también sobretitulación, voice-over, rehablado, interpretación simultánea para festivales, comentario libre (que incluye el tipo de voiceover conocido como Goblin translation, que en realidad es una especie de voice-over libre), subtitulación para sordos, audiodescripción para ciegos, audiosubtitulación, fansubbing y fandubbing son las diferentes modalidades de traducción audiovisual que se cobijan bajo este término. Otras prácticas profesionales relacionadas con la TAV, como la traducción de la publicidad audiovisual, la traducción de cómics, o la localización de videojuegos, se han sumado recientemente a los objetos de estudio de los investigadores de este campo, y se han incorporado también al universo de la traducción multimedia.

El interés científico y académico en la TAV

I Este artículo es la traducción actualizada, ampliada y revisada de la entrada enciclopédica titulada «Research Paths in Audiovisual Transation: The Case of Dubbing», de The Routledge Handbook of Translation Studies, editado por Francesca Bartrina y Carmen Millán Varela en la editorial Routledge (2012).

es cada vez mayor. La proliferación de libros y monográficos, conferencias internacionales ya consolidadas y muy esperadas por la comunidad científica (especialmente, las series estables de Languages and the Media y Media for All), artículos y revistas, ponencias en congresos, cursos profesionales y académicos, grados en traducción e interpretación con asignaturas o itinerarios de especialidad en TAV, másteres en traducción audiovisual, o en traducción creativa que incluyen asignaturas o itinerarios de TAV, tesis doctorales, trabajos fin de máster y trabajos fin de grado en este campo, desarrollo de software profesional, desarrollo de software libre para estas prácticas, doblajes y subtitulaciones para los nuevos dispositivos portátiles que inundan el mercado, como iPhones o iPads, la práctica de la traducción audiovisual para la nueva TDT o para los ya antiguos DVDs, supone un universo de posibilidades para la investigación, y en especial, para la investigación aplicada. Todo esto contribuye, sin lugar a dudas, a una eclosión sin precedentes de este campo de estudio y lleva consigo que la investigación en TAV se haya convertido en un ámbito fascinante para los círculos académicos, y más necesario que nunca para la industria.

El doblaje es una de las modalidades más antiguas de la TAV. Sus orígenes se remontan al final de la década de los años 20 del siglo pasado, a raíz de la necesidad de exportar y traducir a otras lenguas los primeros filmes sonoros de la historia del cine. Los interesantes intentos de realizar versiones multilingües, con los mismos decorados pero con distintos actores, de forma casi siempre simultánea, en distintas lenguas, supusieron un sonoro fracaso para la industria del cine, tanto por su elevado coste, como especialmente por su impopularidad, ya que las audiencias de los distintos países receptores querían ver a los actores y actrices originales y 
no a sus homólogos locales. Con la subtitulación apartada del favor popular en ciertos países con altos índices de analfabetización y poseedores de lenguas mayoritarias, poco acostumbrados al contacto lingüístico y bastante reacios a aprender nuevas lenguas, por lo innecesario del esfuerzo en el día a día de sus habitantes, así como capaces de afrontar los costes altos que supone el doblaje, los ingenieros de sonido inventaron, implementaron y mejoraron un tipo de post-sincronización de sonido que bautizaron con el nombre de doblaje.

Aunque los primeros doblajes fueron técnicamente muy pobres, y además fueron recibidos por la audiencia con mucha frialdad e indiferencia, la interpretación de los actores y actrices de doblaje fue poco a poco ganando en credibilidad. El ajuste se convirtió en una prioridad, los traductores y adaptadores empezaron a reescribir guiones creíbles y convincentes en la lengua meta, ajustados a todo tipo de sincronías (isocronía, sincronía cinésica y sincronía labial); traducciones que creaban la ilusión de estar escuchando diálogos reales o diálogos cinematográficos creíbles que permitían que el espectador se inmiscuyera en la historia narrada en la pantalla y suspendiera su sensación de incredulidad (para el repaso de la historia de la TAV y el doblaje, vid. Izard, r992 y 200I; Ivarsson, 2002; Díaz Cintas, 2003; Díaz Cintas y Remael, 2007 y Chaume 2010). Casi un siglo después, el doblaje ostenta una presencia mundial mayor que nunca (como se verá en el apartado final Planes de futuro) y, además, forma parte de nuevas modalidades complejas de traducción audiovisual, como la localización de videojuegos (en especial, la localización de los videojuegos más comerciales y distribuidos por todo el mundo, que requiere tanto un buen doblaje de los personajes como la subtitulación de letreros, instrucciones, etc.), o la traducción publicita- ria, que tiene lugar incluso en ciertos países subtituladores. El fenómeno del fandubbing se ha internacionalizado y ha democratizado la práctica del doblaje. Los DVDs pueden incluir doblajes en lenguas de países tradicionalmente subtituladores; por ejemplo, se pueden consumir doblajes al portugués de Brasil en DVDs comercializados en Portugal, etc. Parece que todo nos conduce a que en el nuevo mundo de servicios a la carta, las audiencias puedan decidir cómo consumir un producto audiovisual, elegir su modalidad de TAV preferida, su plataforma y el mejor momento para consumirlo.

Esta eclosión de modalidades de TAV, de dispositivos, de plataformas, de nuevas ventanas y de nuevos hábitos, ha atraído inevitablemente la atención de los investigadores. De tal forma que las nuevas contribuciones al campo de la TAV han convertido este ámbito en uno de los más fructíferos en la disciplina de los Estudios de Traducción, donde en el pasado reinaba la traducción literaria. En los párrafos siguientes se realiza un repaso de la investigación llevada a cabo hasta ahora en traducción para el doblaje, así como un esbozo de lo que nos pueden deparar los nuevos senderos por donde empieza a caminar nuestro campo de estudio en este nuevo siglo.

\section{LA INVESTIGACIÓN EN LA TRADUCCIÓN PARA EL DOBLAJE: LOS ORÍGENES}

Aunque los primeros escarceos y reflexiones sobre TAV se remontan al año I960, cuando la revista Babel publicó aquel número especial casi visionario sobre traducción y cine, en el campo del doblaje hay un consenso en considerar el libro de István Fodor Film Dubbing: Phonetic, Semiotic, Esthetic and Psychological Aspects, publicado en 1976, como el monográfico que establece las bases de la práctica profesional del 
doblaje, pero también de su investigación. Veinte años después de que el primer manual sobre subtitulación viera la luz en forma de autopublicación (Laks, I957), Fodor asentó las bases de la investigación en doblaje con un libro que todavía es bibliografía obligatoria en los círculos académicos. El libro adopta una perspectiva netamente profesional, y se centra en el ajuste y en las habilidades necesarias para llevar a cabo un buen doblaje en términos interpretativos y de articulación fonética.

Aparte del interesante artículo de Vöge (1977), la investigación en doblaje avanzó muy poco hasta entrados los años ochenta, cuando se publicaron varios artículos considerados hoy fundacionales (Gautier, I981; Hendrickx, 1984; Hochel, I986; y Mayoral et ál., I986 y I988) y el primer libro escrito en francés por Christophe Pommier, Doublage et postsynchronisation, en I988.

Los años noventa se pueden considerar como la década de la puesta de largo de la TAV y de la traducción para el doblaje: Georg Luyken y un equipo de colaboradores publican Overcoming Language Barriers in Television (I99I), y a este libro le siguen docenas de artículos y capítulos de libro, junto con libros que ahora se consideran también fundacionales de la disciplina, como los de Candace Whitman-Linsen, Through the Dubbing Glass, en 1992; Thomas Herbst, Linguistische Aspekte der Synchronisation von Fernsebserien en 1994; Josephine Dries, Dubbing and Subtitling Guidelines for Production and Distribution en 1995, o la primera y pionera incursión histórica en la traducción para el doblaje escrita por Natàlia Izard, La traducció cinematogràfica, en 1992.

Desde luego, el siglo XXI ha sido testigo de la mayoría de edad y la madurez de la TAV y de la traducción para el doblaje. Si en el siglo pasado la mayoría de aproximaciones a la TAV

pretendían aflorar su especificidad y sus diferencias frente a otras modalidades de traducción para conseguir un estatuto independiente de este campo de estudio, estos primeros años del nuevo siglo se han caracterizado por la búsqueda de vínculos epistemológicos entre la TAV y la Traductología. Mientras que los primeros libros y artículos versaban sobre la descripción de la práctica profesional, los pros y contras del doblaje frente a otras modalidades de TAV, especialmente de la subtitulación, sobre los estándares de calidad de un buen doblaje (o una buena subtitulación, etc.), sobre los procesos industriales de todas las modalidades de TAV, sobre las habilidades del ajuste en doblaje, o sobre las sincronías en la adaptación de diálogos, las obras más recientes intentan acercar posturas entre esta y otras clases de traducción, y entre la TAV y los Estudios de Traducción, y establecer así un equilibrio entre los dos polos: «the independence of AVT as an autonomous discipline and its dependence on other related disciplines» (Romero Fresco, 2006). De hecho, la TAV - y, por tanto, la traducción para el doblaje - es una subdisciplina de los Estudios de Traducción, directamente relacionada con los Estudios de Comunicación, los Estudios Fílmicos y los Estudios sobre Medios Audiovisuales. Pero también con disciplinas afines vinculadas necesariamente a los Estudios de Traducción, como la Sociología, Filosofía, Lingüística, Semiótica, Pragmática, Teoría de la Literatura, etc.

\section{APROXIMACIONES TEÓRICAS}

Los vínculos epistemológicos mencionados se inician con la histórica clasificación de tipos de texto de Reiss (1976), pensada con propósitos traductológicos. Reiss intentó ubicar los textos audiovisuales y, por ende, la traducción audio- 
visual, en una teoría general de la traducción basada en la conocida clasificación de tipos de texto de Bühler. Reiss se dio cuenta de que los textos audiovisuales (y las transferencias de los mismos) no estaban incluidos en ninguna taxonomía de tipos ni de clases de textos y por ello propuso una cuarta categoría que denominó audiomediale texten, que ampliaba la clasificación de los tres tipos de textos tradicionales: informativos, expresivos y operativos. Los textos audiovisuales no cabían en ninguna de las tres categorías mencionadas, porque estos textos pueden ser informativos, expresivos y operativos, o todo a la vez, y se resisten a ser clasificados según una única función (para la autora habría sido más fácil incluirlos en una nueva clase de textos, Textsorte, y no en un nuevo tipo de textos, Texttyp, aunque esta opción tampoco soluciona el problema).

Los textos audiovisuales se encuentran ubicados en otro paradigma, el del modo del discurso y el de la interacción entre iconicidad y escritura: deben ser comparados por oposición a los textos escritos y a los textos orales, y no a las funciones de los mismos. Sin embargo, este intento de equiparar los textos audiovisuales a otros tipos de textos, produjo el efecto contrario y abrió precisamente una línea de investigación que perseguía identificar las características y especificidades de la TAV, y pretendía erigirla en una disciplina autónoma, especialmente alejada de la traducción literaria, cuya supremacía en los Estudios de Traducción conllevaba una mirada hacia la TAV como si esta fuera un apéndice, a veces incluso frívolo, de la traducción literaria. Como reacción a los planteamientos de autoras como Bassnett (I99I) y Snell-Hornby (1988), defensoras de la inclusión de la TAV en el reino de la traducción literaria, autores como Zabalbeascoa, Luyken, Chaume, Agost, Chaves, Karamitroglou, Sokoli, Bartrina,
Espasa, Gambier y Gottlieb, Hurtado, y Díaz Cintas (vid. bibliografía), proclamaron la independencia de la TAV y su estudio autónomo. Estos autores se centran entonces en las características especiales de los textos audiovisuales (la mayoría ya estudiadas en otras disciplinas, como en los estudios sobre medios audiovisuales o en los estudios fílmicos, veinte años antes), relacionan estas características con el proceso de la TAV, y concluyen que esta modalidad de traducción requiere y necesita de su propia metodología.

Siguiendo esta línea de argumentación, otros autores han propuesto marcos metodológicos concretos para el estudio de la TAV: por ejemplo, Delabastita (1990), Karamitroglou (2000), Díaz Cintas (2003) —adaptando el modelo de Lambert y van Gorp, pensado para la traducción literaria-, Chaume (2004a y 2004b), Gutiérrez Lanza (2000), Martí Ferriol (2010) y Barambones (2012), entre otros. Dichos marcos metodológicos toman en cuenta, principalmente, las restricciones de la traducción audiovisual, el encargo de traducción, la posición de la TAV en el sistema meta, su comercialización y su recepción, así como las implicaciones en la traducción de la interacción entre los diferentes códigos y signos que tejen el texto audiovisual.

La mayoría de estas propuestas deben su razón de ser a una línea de investigación previa que se originó en los años ochenta, pero que floreció en los noventa del siglo pasado: la detección y clasificación de las restricciones de la traducción audiovisual. Aunque este concepto se lo debemos a Titford (1982), acuñado para el caso de la subtitulación, son Mayoral, Kelly y Gallardo (I986 y i988) quienes desarrollan este concepto, lo aplican a otras modalidades de traducción audiovisual y a otros géneros textuales o verbo-icónicos (como el cómic), y acuñan el término traducción subordinada, que 
tanto juego ha dado en la investigación en traducción. El concepto de traducción subordinada se ha usado ampliamente en una gran mayoría 18 de ensayos, tesis doctorales y manuales desde entonces (Rabadán, I99I; Zabalbeascoa, I993; Zanettin, I998 y 2008; Hurtado, 200I; Martí Ferriol, 2oro; etc.). El concepto de restricciones lo complementa poco más tarde Zabalbeascoa (I993) con el concepto de prioridades, la otra cara de la moneda de las restricciones vista con mentalidad funcionalista.

Estos conceptos, las restricciones que imponen las imágenes a la traducción, las prioridades estipuladas por el encargo de traducción, el género y el hábito, se han utilizado ampliamente en la investigación en TAV y en traducción para el doblaje en las dos últimas décadas, $\mathrm{y}$ siguen siendo útiles para numerosos investigadores para indagar en otros aspectos y campos de la TAV.

Dentro del espectro de las aproximaciones teóricas se encuentran los escasos y dispersos intentos de describir la historia de la TAV, desde los inicios del cine y los primeros intertítulos (llamados, a la sazón, curiosamente subtítulos) pasando por los primeros filmes sonoros y los primeros doblajes y subtitulaciones, los primeros filmes multilingües, la irrupción de la televisión, del VHs, del DVD, de Internet, de dispositivos móviles como tabletas y smartphones, hasta el cine en $3 \mathrm{D}$ y los videojuegos. Aunque todavía está por escribir una verdadera historia de la TAV, existen contribuciones realmente significativas que arrojan luz sobre el papel de la TAV en el cine a lo largo de la historia, de las razones que subyacen a las preferencias del doblaje sobre la subtitulación o viceversa, o del voice-over sobre ambas en otros países, así como de las razones históricas que subyacen a la existencia de las normas de TAV que regulan los procesos de transferencia de los textos audio- visuales por todo el mundo. Brant, Marleau, Pommier, Izard, Ivarsson, Gottlieb, Díaz Cintas y Chaume (vid. bibliografía) han dibujado mapas parciales de la historia de la TAV, incidiendo en mayor o menor medida en la subtitulación o el doblaje, según sus inquietudes.

La teoría de la TAV se complementa con otro gran campo que ha despertado la curiosidad de varios académicos: la investigación en aquello que podríamos llamar mapas o paisajes de TAV, que describen prácticas llevadas a cabo en diferentes países y regiones del mundo (normalmente dónde, por qué, y cómo se utiliza el doblaje, la subtitulación o el voice-over) o examinan la cartografía de la TAV en un país o región (Barambones, 2012). Estos estudios aportan una fotografía del papel de la TAV y de su función en una cultura determinada, con la descripción de la cantidad de material traducido, de los géneros traducidos (y, por tanto, de cuáles no se traducen), de los pares de lenguas involucrados en el trasvase, del equilibrio entre producción propia y producción ajena en un sistema cultural, y de las razones sociológicas y culturales que subyacen en el acto de la traducción.

\section{ENFOQUES PROFESIONALES}

Aunque los enfoques profesionales suelen tildarse de poco académicos, en tanto que subjetivos, porque suelen explicar siempre el proceso de la traducción para el doblaje según unos estándares profesionales fruto del gusto personal o heredado, sin duda, estos han ayudado a los círculos académicos a desarrollar teorías de la traducción particulares basadas en la abstraccción de esas experiencias. El conocimiento detallado del proceso industrial del doblaje y de la subtitulación constituía un paso previo necesario para poder idear modelos teóricos 
predictivos capaces de analizar las traducciones para estas modalidades de TAV, según las normas que imperan en la profesión. En el caso del doblaje, parte de la investigación se dedicó a los aspectos legales y económicos de esta industria. También se describió el mercado del doblaje, las tarifas y la situación laboral de los profesionales, así como el proceso industrial y los agentes que participan en él. Fodor (1976) abrió esta línea de investigación en el caso del doblaje, seguido por descripciones de la profesión a cargo de Pommier (1988), Whitman-Linsen (1992), Agost (I999), Chaves (2000), Chaume (2004a y 2012), Paolinelli y Di Fortunato (2005), Spadafora (2007), entre otros.

En paralelo, Luyken et ál. (I99I) presentan un estudio pionero que analiza las diversas modalidades de TAV en su relación con los distintos géneros audiovisuales que se pueden ver en las parrillas televisivas, y proponen o sugieren qué géneros deberían doblarse y cuáles subtitularse. $\mathrm{Su}$ enfoque es netamente profesional, basado en datos concretos de recepción y de costes de mercado, con cifras sobre el volumen de programas doblados y subtitulados, así como en datos sobre las preferencias de las audiencias. Dries (1995) se centra en los problemas y obstáculos que presenta la diversidad lingüística en Europa y que impide la libre circulación de producciones europeas entre los países de este continente. La autora propone una serie de directrices pensada para la promoción y la distribución de programas europeos en toda Europa.

Finalmente, aunque la investigación en estándares de calidad es todavía bastante escasa, también merece un pequeño apartado en este repaso. En la era del descriptivismo, la investigación sobre estándares de calidad no constituye una tarea fácil, pues siempre corre el riesgo de caer en juicios subjetivos y prescriptivistas. ¿Estándares de calidad para quién? ¿Es posible acordar entre la comunidad científica y profesional un listado de estándares de calidad? ¿Acaso no dependen de los hábitos y normas específicos de cada país y cada época? A pesar de la dificultad que entrañan estas preguntas, sí que existen ciertos intentos de establecer un conjunto de estándares de calidad en la traducción para el doblaje y en la interpretación en cabina. Todos los autores citados en este apartado han tratado esta cuestión de manera más o menos sistemática. Pero en particular Whitman-Linsen (1992) presenta un listado de tres estándares de calidad en doblaje, ampliado por Chaume (2007a) a seis: un buen ajuste, coherencia entre lo que se escucha y lo que se visiona, lealtad al texto origen (algo que ha perdido peso entre los círculos académicos desde la oleada descriptivista), la escritura de diálogos creíbles y naturales, calidad técnica en la edición de sonido y, finalmente, una ejecución artística o interpretación de los diálogos ni exagerada ni monótona.

Los nuevos medios audiovisuales y los nuevos dispositivos tecnológicos también han atraído la atención de los investigadores para observar cómo se practica el doblaje (u otras modalidades de la TAV) en estas nuevas plataformas y formatos. Existen ya algunas incursiones en los fandubs (Díaz Cintas, 2008a), en el papel del doblaje en la traducción de videojuegos (Granell, 20II) y en las zonas concomitantes entre la traducción teatral y el doblaje (Bartrina y Espasa, 2005) o entre el doblaje y la audiodescripción, por ejemplo.

\section{ESTUDIOS SOBRE EL PROCESO DE LA TRADUCCIÓN CENTRADOS EN EL TEXTO ORIGEN}

Las décadas de 1980 y 1990 del siglo pasado fueron testigo de varios artículos centrados 
en los procesos lingüísticos y semióticos de la TAV. A los investigadores les preocupaba que la TAV se considerara una hermana pequeña de la traducción literaria, y reaccionaban señalando las especificidades de la transferencia de textos audiovisuales. El concepto de traducción subordinada (Mayoral et ál. I986 y r988) descrito anteriormente se fundamenta en la línea argumental de que la traducción en los medios audiovisuales está sujeta y depende en última instancia de las imágenes que acompañan al texto oral o escrito.

La implicación evidente de esta aproximación hacia la TAV es que los traductores deberán elaborar una traducción que sea coherente con las imágenes, en términos de significado, pero también en términos de tiempo y espacio, en términos de ajuste labial e isocronía en el caso del doblaje. Los textos audiovisuales son, por tanto, mucho más que el guión escrito que les sirve de base: un número importante de códigos de significación tejen el significado del texto audiovisual y restringen las posibilidades de traducción, las posibles soluciones que de otro modo serían válidas e incluso más fieles al texto origen (según el paradigma dominante en la época, orientado al texto origen). Dicho de otro modo, estas restricciones no solo deben tenerse en cuenta al traducir, sino que a veces marcan la prioridad en la traducción (Zabalbeascoa, I993), o es prioritario cumplir con la restricción, por encima de lo que se supone que es una buena traducción. Es más, la traducción será considerada una buena traducción si tiene en cuenta la restricción y, por ese motivo, se olvida de otros estándares de calidad.

A pesar de los esfuerzos de estos autores en reivindicar las peculiaridades de la TAV, otros autores seguían analizando exclusivamente el componente lingüístico de estos textos, dada la fuerte tradición lingüística y filológica impe- rante en la época y, por tanto, el enfoque con que los círculos universitarios se aproximaban a la traducción. Algunos trabajos consistían en señalar los errores de traducción de forma prescriptiva. La mayor parte de ellos se centraba en los calcos y en las amenazas para la lengua española (u otras lenguas europeas, como el francés o el danés) por verse constantemente sometida a una suerte de contaminación por parte de la lengua inglesa a partir de la traducción, dado que el inglés es la lengua de los textos originales que se consumen en las pantallas de la mayor parte de países europeos. Dichos autores se quejaban, especialmente, en el caso del doblaje. Las lenguas meta sufrían de constantes invasiones de calcos, sintaxis extraña, frases hechas impropias, estilo lento y pesado, fruto todo ello de traducciones demasiado literales. Tales autores, sin embargo, obviaban la naturaleza semiótica de los textos, y preferían centrarse en los usos normativos de la lengua meta. Mientras que Gottlieb (I997 y 200I) se ha dedicado ampliamente a la subtitulación al danés desde esta perspectiva, otros autores como Whitman-Linsen (1992), Alcandre (200I), o Gómez Capuz (1998), se han centrado en los malos doblajes, a partir de la detección de calcos léxicos, sintácticos y pragmáticos. Seguramente los estudios descriptivos y comparativos pueden arrojar más luz en este sentido; sin embargo, como están orientados al texto meta y al producto de la traducción, se revisarán en el siguiente apartado.

Finalmente, las guías de estilo también están concebidas desde una perspectiva lingüística y, aunque centradas en el texto meta, están diseñadas para formar parte del proceso de traducción. Estas guías son prescriptivas por naturaleza, pero se han de tener en cuenta cuando se traduce para ciertos clientes. Las guías de estilo ofrecen consejos lingüísticos y constituyen el modelo lingüístico de las distintas cadenas de 
televisión o de las distribuidoras más importantes.

A partir de los enfoques lingüísticos, entran en escena ciertos enfoques pragmáticos, de modo paralelo a la evolución que se observa en la Lingüística y la Filología de la época, que pretenden en última instancia demostrar que las elecciones lingüísticas siempre esconden una postura ideológica, es decir, que los distintos usos lingüísticos obedecen a una agenda por parte de los integrantes del proceso de comunicación. En el caso de la subtitulación, estos enfoques pragmáticos denuncian la pérdida de información interpersonal en las traducciones, por ejemplo, los estudios de Mason (I989 y 200I). En el caso del doblaje, aunque desde una perspectiva descriptivista, Martínez Sierra (2008) estudia el trasvase del humor a partir de la pérdida, ganancia o mantenimiento de la carga pragmática de los textos y fragmentos estudiados. Su enfoque discursivo, y su análisis semiótico de las imágenes que acompañan a los ejemplos estudiados, le permiten ofrecer una comprensión global del fenómeno del humor y de cómo viaja el humor entre lenguas y culturas.

Por último, centrados en el texto origen se encuentran también los estudios que relacionan las características de los diferentes géneros audiovisuales con su traducción. Estos estudios pretenden identificar los rasgos particulares de ciertos géneros audiovisuales y relacionarlos con las soluciones de traducción que respeten esas convenciones de género. Luyken et ál. (I99I) presentan la primera clasificación de géneros audiovisuales desde un punto de vista traductológico. Agost (I999) elabora una clasificación interesante de géneros audiovisuales, basada en las premisas sistémico-funcionales de Halliday, con implicaciones para la traducción de estos géneros. Otros autores se han centrado en géneros particulares: Franco (2000) y Espasa (2002) en el voice-over de documentales, Martínez Sierra (2008) en el doblaje de dibujos animados, Martí Ferriol (20Io) en la comparación entre el doblaje y la subtitulación de cine independiente, Zabalbeascoa (1996) y Baños-Piñero y Chaume (2009) en el doblaje de sitcoms - aunque la mayoría de ellos desde posiciones descriptivistas, pero analizando problemas relativos al género audiovisual estudiado.

\section{ESTUDIOS SOBRE EL PRODUCTO DE LA TRADUCCIÓN: EL TEXTO META}

Los Estudios Descriptivos de la Traducción (EDT) se han convertido en el paradigma dominante en la investigación en Traductología. Más que interesarse por los estándares de calidad, por los errores de traducción o por los problemas que plantea el texto origen, los EDT examinan las traducciones como hechos de la cultura en que se originan y, en este sentido, los EDT consideran las traducciones como productos concretos de las normas y convenciones de la cultura meta. No solo se preocupan de las normas lingüísticas y textuales que dirigen la traducción hacia un lado u otro, sino que también indagan en las razones sociológicas, políticas y económicas que hay detrás de esas normas.

Los EDT están basados en la teoría del polisistema y, por tanto, se preocupan de cómo los diferentes sistemas (culturales, literarios y, especialmente en nuestro caso, audiovisuales) se influyen entre sí, así como de las relaciones entre culturas origen y meta. Delabastita abrió este debate en el terreno de la TAV con sus artículos fundacionales de 1989 y r99o. En el caso del doblaje, este enfoque implica un número enorme de líneas de investigación, la mayoría de las cuales están comenzando a dar sus frutos. Alsina (2005) y Cañuelo (2005 y 2009) han realizado contribuciones en este campo; por 
ejemplo, Cañuelo compara cuatro conjuntos diferentes de textos interrelacionados: filmes originales en español, sus versiones dobladas al alemán, las novelas originales españolas en las que los filmes están basados y la traducción de estas novelas al alemán. Estos cuatro sistemas interactúan y se influyen los unos a los otros, ya que, por ejemplo, las novelas a veces se escriben después del estreno del filme, y no siempre antes, los doblajes a veces se realizan después de haberse traducido la novela, o viceversa, con las influencias que ello supone para la traducción, etc. Estas interacciones demuestran cómo los diferentes sistemas influyen entre sí, muestran la posición y la jerarquía de cada sistema y producto en cada cultura y, por tanto, abren una línea de investigación ciertamente prometedora.

El mapeo o radiografía de la traducción audiovisual, y del doblaje concretamente, es otro de los grandes campos que los investigadores empiezan a explorar. Barambones (2012) ha sido pionero en este tipo de investigación en el campo del doblaje. El autor analiza la cantidad de doblajes emitidos en ЕTBI —el primer canal de televisión vasco-, la parrilla de televisión, qué géneros se doblan, en qué momento se emiten los doblajes y por qué, cómo se utilizan los doblajes en esta cadena, el modelo lingüístico que se usa en los doblajes, y presenta un mapa completo de la posición del doblaje en este canal, junto al contexto que explica las razones ideológicas que subyacen a la función y posición del doblaje en ЕТВi.

Una posible línea de investigación es también el nacimiento de nuevos géneros audiovisuales a partir de las traducciones de géneros audiovisuales extranjeros (Delabastita, I990; Cattrysse, I992; Baños-Piñero y Chaume, 2009). Podría argumentarse que algunas sitcoms en países dobladores deben su existencia al éxito previo de los doblajes de otras sitcoms extranjeras.
Emergen, por tanto, nuevos géneros como consecuencia de doblajes (o subtitulaciones) de textos extranjeros, es decir, como consecuencia de la traducción. Algunos dibujos animados producidos en ciertas culturas meta son producto de los doblajes previos del mismo género a esas culturas.

La ideología también desempeña un papel esencial en la investigación del doblaje, como un paso más del paradigma descriptivista. La censura siempre ha constituido una parte integral del doblaje en los regímenes fascistas y totalitarios. Danan (I99I), Ballester (200I) o Gutiérrez Lanza (2005) y el grupo TRACE (Rabadán, 2000), muestran cómo la censura ha modelado la traducción y cómo se ha utilizado en el doblaje. La ideología va más allá de la censura en estos regímenes: es interesante también observar cómo diferentes culturas hacen frente a las cuestiones de género en doblaje (De Marco, 20I2), las preferencias de las diferentes cadenas de TV con respecto a las opciones lingüísticas utilizadas (Marzà et ál. 2006), cómo se traducen las referencias culturales de una lengua y cultura minoritaria a una mayoritaria (Santamaría, 200I), cómo viaja el humor entre culturas (Zabalbeascoa, I993; Chiaro, 2008; Fuentes, 2005; Martínez Sierra, 2008), etc.

Las normas de traducción se han erigido, sin lugar a dudas, en uno de los conceptos más aceptados, trabajados y fructíferos en los EDT $y$, por tanto, en los estudios descriptivos de traducción audiovisual. En el campo del doblaje, las normas de traducción se exploraron por primera vez en 1993, en otro artículo fundacional de este campo de estudio a cargo de Goris. El autor identifica tres normas de traducción en los doblajes franceses de películas norteamericanas: la estandarización (o nivelación de rasgos lingüísticos subestándar en el filme original), la explicitación (o desambiguación de 
diálogos oscuros, palabras y frases polisémicas o ambiguas) y la adaptación (o familiarización, en términos de referentes culturales, ajuste, etc.). Otros académicos han llevado a cabo diversas investigaciones sobre normas de traducción para el doblaje, como Ballester (200I), Pavesi (2005), Gutiérrez Lanza (2000 y 2005) o Martí Ferriol (2010).

Algunas nociones o conceptos de la teoría de la traducción se han aplicado al doblaje en este marco descriptivista. Por ejemplo, Martí Ferriol (20I0) ha estudiado la noción de método de traducción en un análisis comparativo de doblajes y subtitulaciones de cine independiente; Chaves (2000), Pereira y Lorenzo (2005), Spadafora (2007) y Martí Ferriol (2010) ofrecen también un listado de técnicas de traducción específico para el doblaje; Marzà (2009) aplica el concepto de mecenazgo al caso del doblaje en lenguas minoritarias; Soh-Tatcha (2009) trata el concepto de equivalencia en doblaje; Espasa (2008) examina el diseño de audiencia en doblaje.

Afortunadamente, las nuevas tecnologías han entrado también en la investigación en TAV. La tecnología digital, junto con nuevo software, posibilita que las normas de traducción se examinen a gran escala (de hecho, para llamarlas normas deberían siempre examinarse así), ya que los esfuerzos para identificar normas siempre se han tenido que restringir a un número limitado de filmes u otros géneros audiovisuales. Los estudios de corpus han ayudado a los investigadores a validar (o no) las hipótesis que habían extraído de diferentes estudios de caso individuales, especialmente, tesis doctorales. La digitalización de filmes, guiones originales $\mathrm{y}$ traducciones han permitido a investigadoras como Pavesi (2005), Freddi y Pavesi (2009), Bruti (2009) y Valentini (2006) entre otras académicas italianas, realizar una fotografía mucho más precisa de las normas del doblaje.
La lengua del doblaje, conocida como dubbese en inglés o synchronien en francés, es uno de los campos más atractivos y fructíferos en los estudios de corpus. El dubbese es el modelo de lengua que cada cultura prefiere aplicar a sus doblajes y está fuertemente influido por la política lingüística de cada lengua, país y cultura. En trabajos anteriores, he utilizado el término oralidad prefabricada en referencia al falso discurso oral que encontramos en los doblajes, que se encuentra a medio camino entre la escritura y la oralidad, entre la planificación y la espontaneidad. Las investigadoras italianas mencionadas anteriormente han dibujado el mapa más completo del dubbese hasta la fecha. En España, en lengua catalana se ha trabajado con más insistencia y frutos que en lengua española, con las aportaciones de Bassols et ál. (1997), Chaume (2003a), Izard (2004), Cuenca (2006), Marzà et ál. (2006), Matamala (2009), Marzà y Chaume (2009). En euskera, el libro ya mencionado de Barambones (2012) trata de forma exhaustiva el modelo de lengua del doblaje. En español, Romero Fresco (2006), Pérez González (2007), Baños-Piñero y Chaume (2009) y Romero Ramos (2010) han indagado en estas mismas cuestiones. Baños (2012) adopta un enfoque polisistémico para comparar el doblaje de la comedia de situación norteamericana Friends con su contrapartida española, la producción propia de Siete Vidas, y realiza un análisis detallado de la lengua del doblaje y de la lengua de la producción propia, estructurado en los cuatro niveles clásicos de la lengua: fonética, morfología, sintaxis y semántica. Quaglio (2009) también analiza la comedia de situación Friends y la compara con un corpus oral de inglés norteamericano de conversaciones reales. Examina también ejemplos de registros informales y rasgos que expresan emociones. Aunque no se centra en la traducción a ninguna 
lengua, el autor analiza con detalle el lenguaje de las comedias de situación, especialmente ese registro oral fingido tan característico de las producciones audiovisuales de ficción. En francés, von Flotow (2009) explora las diferencias entre el modelo lingüístico de los doblajes en Francia y el Québec.

Sin embargo, la investigación sobre la lengua del doblaje no es nueva. En la década de 1960, se creó un modelo lingüístico artificial para doblar al español filmes, series de TV y dibujos animados norteamericanos. Se trataba de un modelo particular, inexistente, que pretendía emular los dialectos principales de la lengua española. Este español se bautizó como español neutro y combinaba rasgos lingüísticos de diferentes dialectos del español hablados en España y Latinoamérica. El resultado fue un constructo extraño, que no empleaba ningún hablante en particular, pero que no era mal recibido tampoco por ninguno de ellos. Este dialecto falso fue especialmente notorio en los doblajes de los clásicos de Disney. Ávila (1998), entre otros autores, ha estudiado este fenómeno interesante, que para muchas generaciones en España se identifica con la lengua de los dibujos animados de su infancia.

Otro fenómeno fascinante y relativamente poco explorado es la interacción entre los diferentes códigos de significación del lenguaje cinematográfico y sus implicaciones en traducción. Una gran parte de la investigación en traducción audiovisual se ha centrado en el código lingüístico de los textos audiovisuales, es decir, en sus diálogos. Sin embargo, un texto audiovisual es mucho más que una serie concatenada de diálogos: además del código lingüístico, se pueden apreciar varios códigos más que tejen el significado del texto audiovisual y que son fundamentales para la transmisión de este texto a otras lenguas, o a otras audiencias (las audiencias con discapacidades auditivas o visuales): los códigos paralingüísticos, el código musical, el código de efectos especiales, el código de colocación del sonido, el código iconográfico, el código fotográfico, el código de movilidad (cinésica y proxémica), el código de planificación (los tipos de planos y su significado e influencia en la traducción), los códigos gráficos (títulos, insertos), o el código de montaje (Chaume, 20I2). Todos los signos pertenecientes a estos códigos se utilizan en un filme de manera intencionada, y muchos de ellos tienen una repercusión clara en la traducción. Del mismo modo, la traducción también se tiene que tener en cuenta a la hora de realizar y montar un filme, pensando ya en hacerlo accesible o en evitar problemas de traducción inter o intralingüística. La investigación en este campo demuestra que ciertas normas del doblaje deben su razón de ser a la fuerza y presencia de estos códigos no lingüísticos, semióticos, como la música, los colores, los primeros planos, etc. Gambier y Suomela-Salmi (r994), Chaves (2000), Remael (2004), Cattrysse y Gambier (2008), y Mubenga (2009) han indagado en estas cuestiones también, que de hecho han tomado forma en un itinerario de especialización del M.A. in Audiovisual Translation de la Roehampton University de Londres.

Los estudios de recepción en el campo de la traducción audiovisual han recibido poca atención por el momento. Pocos autores se han lanzado a la aventura de diseñar cuestionarios para descubrir cómo se reciben los doblajes (o las subtitulaciones, o los nuevos voice-overs de los realities) por parte de las audiencias. Neves (2005) condujo un experimento admirable para comprobar la recepción de los subtítulos para sordos entre sujetos con deficiencias auditivas en Portugal, y cuyos resultados acabaron convirtiéndose en una propuesta de estándares 
de calidad para la subtitulación para sordos que adoptó al menos una cadena de televisión portuguesa. En el campo del doblaje, los estudios de recepción todavía tienen un alcance tímido. Fuentes (2005) fue el primer autor que introdujo cuestionarios para medir la recepción del doblaje del filme de los Hermanos Marx Duck Soup (Sopa de Ganso), centrándose en la transferencia del humor y utilizando dos grupos de sujetos, uno angloparlante y el otro hispanoparlante. Mayoral (200I) ofrece una panorámica de los problemas que plantea el diseño de audiencia en traducción audiovisual, las nuevas ventanas y formatos audiovisuales, las diferentes audiencias y hábitos, etc. Espasa (2008) investiga también el diseño de audiencia y los diferentes destinatarios que la traducción va teniendo a lo largo del proceso industrial y artístico del doblaje. Las cuestiones sociales de la recepción las tocan Luyken et ál. (1995) y Zaro (200I), que es el primer autor que utiliza y aplica los conceptos de Bourdieu a la TAV y al doblaje. Antonioni y Chiaro (2009) utilizan cuestionarios para llevar a cabo un interesante estudio de recepción en Italia también.

Finalmente, para consolidar la investigación en TAV y en doblaje son necesarios también los estudios de caso, que son tan heterogéneos como los posibles temas a investigar en traducción en general, y en traducción audiovisual en particular. La traducción para el doblaje incluye, por tanto, investigaciones sobre títulos de películas (Nord, 1990 y 1995; Fuentes, 19971998; González, 2005; Santaemilia y Soler, 2oro, etc.), humor (Zabalbeascoa, 1996; Chiaro, 2005 y 2008; Fuentes, 2005; Martínez Sierra, 2008), juegos de palabras y frases hechas (Sanderson, 2009; Delabastita, 1996), nombres propios (Hurtado de Mendoza, 2009), referencias culturales (Santamaría, 20or; Antonini y Chiaro, 2005, etc.), lenguaje tabú (Chiaro, 2007), y otros temas menos investigados como la intertextualidad, las canciones, etc.

Los filmes multilingües constituyen un nuevo campo de investigación en TAV y en doblaje. Heiss (2004), Valdeón (2005), Corrius (2008), Martínez Sierra et ál. (2010) han abierto una nueva línea que explora los temas de multilingüismo y multiculturalidad en el cine moderno.

Los EDT todavía pueden aportar mucho a la descripción del doblaje en todo el mundo. La búsqueda incesante de normas de traducción y de las razones ideológicas que subyacen a su uso todavía constituye un camino prometedor y sigue erigiéndose como uno de los grandes intereses de los investigadores. Los estudios sobre corpus, utilizados como herramienta dentro de la metodología descriptivista, se convierten en una de las avenidas de investigación con mayor potencial en nuestro ámbito.

\section{LA ENSEÑANZA DE LA TRADUCCIÓN PARA EL DOBLAJE: LA INVESTIGACIÓN EN DIDÁCTICA}

Cuando la traducción para el doblaje entró en las aulas universitarias en la década de I990, los profesores tuvieron que reflexionar sobre cómo preparar a los estudiantes para una profesión relacionada tanto con la tecnología de la imagen y el sonido, como con la interpretación artística. La primera decisión fue, por tanto, decidir qué se podía enseñar en la universidad. ¿Era conveniente enseñar todas las habilidades para hacer frente al proceso completo del doblaje? ¿Sería mejor enseñar traducción, adaptación, locución e interpretación, dirección de doblaje y edición de imagen y sonido, o solo la traducción, opción más propia de las antiguas diplomaturas y licenciaturas, pensadas y diseñadas siempre desde la óptica de la gestión de los textos escritos? 
En la mayoría de las universidades, la enseñanza del doblaje se ha limitado a la enseñanza de dos competencias generales: cómo traducir para el doblaje, y cómo realizar la adaptación o ajuste de diálogos. Las asignaturas de traducción para doblaje intentan también cubrir tareas propias del ajustador o del ayudante de doblaje, como la segmentación del texto en takes, la adición o notación de símbolos del doblaje en la traducción - aquellos que ayudan a los actores a realizar determinados gestos o ajustar con mayor o menor exactitud-, el ajuste de los diálogos a las bocas de los personajes en pantalla, o la elaboración de un discurso oral y fresco, que se asemeje al lenguaje oral, siempre dentro de las características del filme en cuestión. Tanto los grados como los postgrados de traducción audiovisual han renunciado siempre, conscientemente, a incluir entre sus asignaturas contenidos sobre la parte artística del doblaje, la ejecución de los diálogos, la locución, la interpretación artística, competencias que se suelen enseñar en las escuelas de teatro y cine. Las cuestiones de tecnología de imagen y sonido también han quedado fuera de estos cursos, ya que tradicionalmente se imparten en ciclos de formación profesional o, más recientemente, en los grados de comunicación audiovisual. Por este motivo, la traducción y la adaptación de diálogos son los dos campos sobre los que ha dedicado su atención la didáctica de la traducción para el doblaje.

En este ámbito, los artículos pioneros de Zabalbeascoa (I997, 2000 y 200I) se pueden considerar también fundacionales. De manera muy significativa, el autor ha dedicado mucha de su producción científica a la formación de estudiantes y profesores. Sus propuestas, en línea con la tradición vigente desde hace una o dos décadas, consisten en analizar el texto origen y establecer un conjunto jerarquizado de prioridades y restricciones que guíen a los estudiantes en sus soluciones de traducción.

En el volumen colectivo de Gambier (1998) encontramos un bloque entero dedicado a la enseñanza de la TAV. Autores como Kovacic, James, Klerx y Carroll tratan la cuestión de cómo se debe formar a los estudiantes en el aula de TAV. Otros volúmenes colectivos también incluyen secciones enteras dedicadas a la didáctica de la TAV, y en especial del doblaje, como el de Agost y Chaume (200I), con contribuciones de Espasa, Bartrina e Izard, o el de Zabalbeascoa, Santamaría y Chaume (2005), con contribuciones de Bueno, Pereira y Lorenzo, y Valverde.

Chaume (2003b) trata la cuestión de los perfiles del profesor y de los estudiantes de TAV, junto con una propuesta metodológica para enseñar traducción para el doblaje, con los materiales que se pueden utilizar en clase, la evaluación de la traducción y una propuesta de baremo para corregir las traducciones para el doblaje.

Bartrina y Espasa han realizado varias incursiones de gran valor en la didáctica de la TAV y del doblaje (2003 y 2005). En su detallada propuesta de 2003, las autoras se basan en su experiencia docente y proponen actividades y ejercicios para desarrollar las habilidades que se requieren en TAV, incluida la adaptación de diálogos. Las autoras presentan también materiales, textos origen, recomendaciones sobre cómo realizar los ejercicios, etc.

Díaz Cintas (2008b) ha editado el primer volumen en inglés dedicado exclusivamente a la didáctica de la TAV. Aunque solo un artículo se dedica al doblaje (Chaume, 2008), este volumen incluye sugerencias, recomendaciones, y ejercicios para la enseñanza de la TAV que son igualmente aplicables al doblaje, así como numerosas contribuciones teóricas sobre la didáctica y la metodología de la enseñanza de la TAV. 
Cerezo Merchán (2012) ha elaborado la primera tesis doctoral centrada exclusivamente en la didáctica de la TAV. La autora analiza la formación universitaria en el ámbito de la traducción audiovisual y las exigencias del sector profesional en España, con el propósito de realizar propuestas para mejorar la calidad del servicio profesional y la formación de los futuros profesionales. A través de un exhaustivo análisis documental, así como de entrevistas y cuestionarios a profesores, traductores y empleadores del sector de la TAV, en esta tesis se identifican los perfiles de estos tres grupos de población, se buscan las competencias necesarias para el traductor de textos audiovisuales, se reflexiona sobre el papel de la tecnología en la enseñanza de la TAV, se estudian las metodologías más apropiadas para la impartición de este tipo de trasvase y se hacen propuestas de mejora para la formación en esta modalidad.

Martínez Sierra (2012a) ha elaborado el primer manual de enseñanza de la traducción audiovisual en español, en el que se incluyen la gran mayoría de modalidades de TAV, con ejercicios, lecturas recomendadas para cada unidad didáctica y contenidos básicos sobre cada una de las modalidades.

Un campo todavía poco explorado es el de la enseñanza y adquisición de lenguas extranjeras a partir de la subtitulación y, sobre todo, del doblaje. Todos los proyectos experimentales llevados a cabo hasta ahora, así como las aproximaciones teóricas, han analizado la utilidad de la subtitulación como herramienta para la adquisición de una lengua extranjera. La traducción había sido condenada al ostracismo durante varias décadas en el campo de la adquisición de lenguas extranjeras, ya que los enfoques comunicativos ignoraban intencionadamente cualquier intento de traducción en la clase de lengua extranjera. Pero esta tendencia parece haberse revertido en los últimos años y empezamos ya a encontrar proyectos internacionales (Levis, ClipFlair, Subtitles and Language Learning), así como artículos y tesis doctorales (Bravo, 2008; Talaván, 2009), que demuestran la utilidad de la subtitulación en este campo. La reciente aportación de Ghia (2012) es un ejemplo claro del interés en este campo. Y aunque parece difícil que el doblaje pueda servir como instrumento para la adquisición de una segunda lengua, experimentos como el Danan (2010) abren el debate y muestran cómo la traducción para el doblaje puede ser también útil para este propósito, algo que hace tan solo unos años habría sido inconcebible.

\section{PLANES DE FUTURO}

La traducción para el doblaje ocupa un lugar muy visible en el universo de la TAV. Lejos de haber desaparecido del mapa, como algunos académicos preconizaban, el doblaje sigue practicándose en todo el mundo, e incluso creciendo en algunos lugares. Los dibujos animados para las audiencias más jóvenes se doblan en casi todo el mundo, incluidos los llamados países subtituladores. En Rusia, el doblaje quiere ganarle terreno al voice-over. En Polonia, las encuestas demuestran que la audiencia prefiere el doblaje al voice-over, aunque en ese país es la subtitulación la que empieza tímidamente a tomar el relevo del voice-over. Las telenovelas sudamericanas y turcas se están doblando en países tradicionalmente subtituladores como Grecia, Marruecos y otros países del norte de África. En Dinamarca, un país con una enorme tradición subtituladora, se han doblado algunos filmes para adolescentes (teen pics), y en Noruega se ha doblado también este género de filmes y comedias de situación (Tveit, 2009). Las nuevas tecnologías permiten que se pueda 
incluir en el mismo producto (DVD, Blue-Ray, Internet) tanto el doblaje como la subtitulación, como otras modalidades de la TAV, de modo que las diferentes audiencias puedan elegir cómo desean consumir un texto audiovisual extranjero. Otros nuevos géneros audiovisuales, como los videojuegos, especialmente los más elaborados, se doblan también. La profecía auspiciada por algunos sobre la desaparición del doblaje en los países dobladores se ha disuelto y ha dado lugar a un escenario que ofrece oportunidades - y combinaciones entre modalidades de TAV - para satisfacer las necesidades de todas las audiencias.

Esto implica, necesariamente, la apertura de nuevos senderos para la investigación. Los mayores retos con los que nos enfrentamos ahora son remapear la presencia del doblaje en el mundo y describir los nuevos procesos en los que toma parte el doblaje. Algunos géneros nuevos, como los videojuegos, se localizan utilizando el doblaje y la subtitulación, quizá pronto con voice-over también, y además se hacen accesibles para personas con discapacidad visual o auditiva. Sin embargo, el doblaje de videojuegos conlleva un proceso distinto al doblaje tradicional. En ocasiones, el doblaje se realiza en paralelo con la sonorización del texto original, como en las antiguas versiones multilingües del primer cine sonoro. Además, otras veces, no hay restricciones temporales para el doblaje, especialmente la isocronía. En otras ocasiones, ciertas partes concretas del juego requieren doblajes específicos y el texto se traduce sin takes ni códigos de tiempo. Urge describir este nuevo proceso industrial, junto con sus implicaciones sociológicas, ideológicas y económicas.

Richart (2009) ha descubierto una zona inexplorada todavía en el proceso de la traducción para el doblaje y, con una metodología empírica, demuestra que la traducción para

el doblaje es realmente un palimpsesto en el que cada nueva traducción o modificación de la traducción se sobreescribe a la anterior. De esta forma, la autora explora cómo se crea la traducción y cómo el adaptador, el director de doblaje y los actores reescriben esta traducción hasta que consideran que cumple con todas las sincronías y con los estándares de calidad de un texto oral verosímil y adecuado al estilo de los personajes de pantalla. Todavía nos queda mucho por aprender de este análisis genético del doblaje porque, aunque el proceso en sí se había descrito ampliamente, es la primera vez que se revelan las diferentes traducciones y retraducciones reales de un guión meta.

E1 ajuste o adaptación también necesita mayor atención académica. En muchos países dobladores, la adaptación de diálogos conlleva hasta cuatro tareas - como ya se ha mencionado-, que realizan el adaptador o el ayudante de doblaje, según cada realidad: a) la segmentación de la traducción en takes (loops en América, boucles en Francia, anelli en Italia), que forman las unidades de la traducción que los actores doblan de una vez; b) la inserción o notación de los símbolos del doblaje, o indicaciones para la interpretación y el ajuste por parte de los actores, como por ejemplo, si el actor original se encuentra en campo o fuera de campo, si realiza pausas al hablar, etc.; c) el ajuste; y, finalmente, d) la creación de diálogos naturales, verosímiles, que a la vez cumplan con la normativa gramatical de la lengua meta (en Chaume, 2007b, se muestra un estudio comparativo de estas convenciones en varios países dobladores europeos). En algunos países, las dos primeras tareas las realiza el asistente de doblaje, mientras que en otros, las cuatro tareas las realiza el ajustador. En este ámbito, todavía necesitamos más estudios descriptivos sobre las normas matriciales que operan en la traducción para el doblaje. Las 
normas matriciales rigen la existencia del material en la lengua meta, su posición y distribución en el texto, así como la segmentación de la traducción. Estas normas también determinan el grado de presencia y ausencia de omisiones, adiciones, cambios y manipulaciones del texto meta. Es interesante observar cómo el proceso de la adaptación influye y modifica la traducción, cómo el uso de símbolos de doblaje también la modifica, y cómo el ajuste y la búsqueda de la naturalidad en los diálogos acaba dándole una pátina distinta y convirtiendo la traducción en ese registro especial que hemos acabado aceptando como la lengua del doblaje.

Junto a esta línea de investigación se sitúa la reflexión sobre las relaciones entre la escritura de guiones y la traducción para el doblaje (y la subtitulación). ¿Hasta qué punto existe una intersección entre ambas actividades? ¿Necesita el traductor formación sobre escritura de guiones? Hasta la fecha, poco se ha escrito sobre el tema, aparte de las contribuciones de Remael (2004) o Martínez Sierra (2012b).

Otro de los campos de interés que debe dar muchos más frutos de los que ha dado todavía es el uso de la traducción audiovisual como instrumento que facilite el aprendizaje de lenguas, como hemos visto en el apartado dedicado a la didáctica de la TAV.

Los fandubs (término que, a veces, aparece escrito intencionadamente bajo la forma fundub) constituyen otro campo fascinante de investigación. Un fandub o fundub es un doblaje casero de un filme, serie de TV, dibujos animados o especialmente tráileres, realizado por un fan. La calidad varía de los fandubs realizados sin efectos especiales y con micrófonos de baja calidad, a fandubs doblados por actores profesionales, que utilizan equipos de sonido profesionales y regalan su tiempo para conseguir un buen producto final. Los fandubs, de hecho, pueden empezar a influir en los doblajes convencionales del mismo modo que los fansubs empiezan a influir en la subtitulación convencional. Las razones ideológicas que se esconden detrás de la creación de los fandubs también necesitan mayor atención por parte de la comunidad universitaria.

Por último, más allá del descriptivismo, encontramos el giro cultural y los estudios sobre ideología, que han empezado a entrar en el campo de la TAV y de la traducción para el doblaje. El giro cultural, las cuestiones de género en la TAV (De Marco, 20I2) y conceptos como poder, otredad, mecenazgo, resistencia, identidad (especialmente en filmes multilingües -De Higes, en prensa-) o postcolonialismo, exigen la atención urgente de los investigadores en el campo que aquí nos ocupa. Otros conceptos teóricos como la extranjerización y la familiarización de Venuti o Carbonell, la deconstrucción de Derrida, el campo, el hábito o la doxa de Bourdieu, o el concepto de reescritura de Lefevere, todavía siguen prácticamente inexplorados en TAV.

RECIBIDO EN DICIEMBRE DE 2012 ACEPTADO EN ENERO DE 2013 VERSIÓN FINAL DE DICIEMBRE DE 2012

\section{REFERENCIAS BIBLIOGRÁFICAS}

Agost, R. (1999). Traducción y doblaje: palabras, voces e imágenes. Barcelona: Ariel.

Agost, R. y Chaume, F. (200I). La traducción en los medios audiovisuales. Castellón de la Plana: Publicacions de la Universitat Jaume I.

Alcandre, J. J. (200I). «Sous-titrage: Le cas de la traduction de l'allemand vers le français». En R. Agost y Chaume, F. (eds.). La traducción en los medios audiovisuales. Castellón de la Plana: Publicacions de la Universitat Jaume I, pp. I29-I34.

Alsina, V. (2005). «Adaptaciones literarias en el cine: El caso de Jane Austen». En Zabalbeascoa, P.,

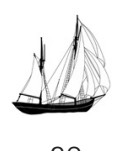

29 


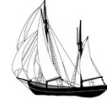

30
Santamaría, L. y Chaume, F. (eds.). La traducción audiovisual: Investigación, enseñanza y profesión. Granada: Comares, pp. 53-64.

Antonioni, R. y D. Chiaro (2009). «The perception of dubbing by Italian audiences». En Díaz Cintas, J. y Anderman, G. (eds.). Audiovisual Translation. Language Transfer on Screen. Basingstoke: Palgrave Macmillan, pp. 97-II4.

Ávila, R. (I998). "Televisión internacional, lengua internacional». En Cortés, L., Mapes, C. y García Tort, C. (coords.). La lengua española y los medios de comunicación. Méjico: Ed. S. XXI, pp. 9II-93I.

Ballester, A. (200I). Traducción y nacionalismo. La recepción del cine americano en España a través del doblaje (1928-1948). Granada: Comares.

Baños, R. (2012). «La oralidad prefabricada en la traducción para el doblaje y en producciones propias. El caso de Friends y Siete Vidas». En Martínez Sierra, J.J. (coord.). Fotografía de la investigación doctoral en traducción audiovisual. Madrid: Bohodón Ediciones, pp. 99-II7.

Baños Piñero, R. \& Chaume, F. (2009). «Prefabricated Orality: A Challenge in Audiovisual Translation» [en línea]. Intralinea, Special Issue: The Translation of Dialects in Multimedia, <http:// www.intralinea.it/specials/dialectrans/ita_more. php?id=76I_o_49_o_M>, [Consulta: 30 oct. 2OI2].

Barambones, J. (2012). Lenguas minoritarias y traducción audiovisual. El caso del euskera. Castellón de la Plana: Publicacions de la Universitat Jaume I, Colllecció TRAMA.

Bartrina, F. (200I). «La investigación en traducción audiovisual: interdisciplinariedad y especificidad». En Sanderson, J. (ed.). ¡Doble o nada! Actas de las I y II Jornadas de doblaje y subtitulación. Alicante: Publicacions de la Universitat d'Alacant, pp. 27-38.

Bartrina, F. y E. Espasa (2003). «Traducción de textos audiovisuales». En González Davies, M. (coord.). Secuencias. Tareas para el aprendizaje interactivo de la traducción especializada. Barcelona: OctaedroEUB, pp. 19-38.

Bartrina, F. y E. Espasa (2005). «Audiovisual Translation». En Tennent, M. (ed.). Translating for the New Millennium. Ámsterdam y Filadelfia: Benjamins, pp. 83-гoo.

Bassnett, S. (I99I). Translation Studies. Londres y Nueva York: Routledge.
Bassols, M., Rico, A. y Torrent, A. (1997). La llengua de $T V_{3}$. Barcelona: Empúries.

Brant, R. (1984). The History and Practice of French Subtitling. Tesina de máster inédita. Austin: University of Texas.

Bravo, M.C.C. (2008). Putting the reader in the picture. Screen translation and foreign-language learning. Tesis doctoral inédita.

Bruti, S. (2009). «Translating compliments and insults in the Pavia Corpus of Film Dialogue: two sides of the same coin?». En Freddi, M. y Pavesi, M. (eds.). Analysing audiovisual dialogue. Linguistic and translational insights. Bolonia: Clueb, pp. I43-I64.

Cañuelo, S. (2005). «Adaptación cinematográfica y traducción: Hacia una sistematización de sus relaciones». En Zabalbeascoa, P., Santamaría, L. y Chaume, F. (eds.). La traducción audiovisual: Investigación, enseñanza y profesión. Granada: Comares, pp. 65-79.

Cañuelo, S. (2009) «Transfer norms for film adaptation in the Spanish-German context». En Díaz Cintas, J. y Anderman, G. (eds.). Audiovisual Translation. Language Transfer on Screen. Basingstoke: Palgrave Macmillan, pp. II5-I29.

Cattrysse, R. (1992). Pour une théorie de l'adaptation filmique. Le film noir américain. Berna: Peter Lang.

Cattrysse, P. y Gambier, Y. (2008). «Scriptwriting and translating screenplays». En Díaz Cintas, J. (ed.). The Didactics of Audiovisual Translation. Ámsterdam y Filadelfia: Benjamins, pp. 39-55.

Cerezo Merchán, B. (2012). La didáctica de la traducción audiovisual en España: Un estudio de caso empirico-descriptivo. Tesis doctoral inédita.

Chaume, F. (2003a). Doblatge i subtitulació per a la $T V$. Vic: Eumo.

Chaume, F. (2003b). «Teaching audiovisual translation: Some methodological proposals». En Pérez González, L. (ed.). Speaking in Tongues: Language across Contexts and Users. Valencia: Publicacions de la Universitat de València, pp. 271-302.

Chaume, F. (2004a). Cine y traducción. Madrid: Cátedra.

Chaume, F. (2004b). «Film Studies and Translation Studies: Two Disciplines at Stake in Audiovisual Translation», Meta, 49 (I), pp. I2-24.

Chaume, F. (2007a). «Quality standards in dubbing: a proposal», TradTerm, I3, pp. 7I-89.

Chaume, F. (2007b). «Dubbing practices in Europe: 
Localisation beats globalisation», Linguistica Antverpiensia, 6, pp. 20I-2I7.

Chaume, F. (2008). «Teaching synchronisation in a dubbing course». En Díaz Cintas, J. (ed.). The Didactics of Audiovisual Translation. Ámsterdam: Benjamins, pp. I29-I40.

Chaume, F. (2010). «Traducción audiovisual». En Pegenaute, L. y Lafarga, F. (eds.). Diccionario Histórico de la Traducción en España. Madrid: Gredos.

Chaume, F. (2012). Audiovisual Translation: Dubbing. Manchester: St. Jerome.

Chaves, M.J. (2000). La traducción cinematográfica. El doblaje. Huelva: Publicaciones de la Universidad de Huelva.

Chiaro, D. (ed.) (2005). Humor and Translation, Special Issue of Humor: International Journal of Humour Research, I8 (2).

Chiaro, D. (2007). "Not in front of the children? An analysis of sex on screen in Italy», Linguistica Antverpiensia, 6, pp. 255-276.

Chiaro, D. (2008). "Humor and translation». En Raskin, V. (ed.). The Primer of Humor Research. Berlín y Nueva York: Mouton de Gruyter, pp. 573-612.

Corrius, M. (2008). Translating Multilingual Audiovisual Texts. Priorities, Restrictions, Theoretical Implications. Tesis doctoral inédita.

Cuenca, M.J. (2006). «Interjections and pragmatic errors in dubbing», Meta, $5^{\mathrm{I}}$ (I), pp. 20-35.

Danan, M. (I99I). «Dubbing as an Expression of Nationalism», Meta, 36 (4), pp. 6o6-6I4.

Danan, M. (2010). «Dubbing projects for the language learner: a framework for integrating audiovisual translation into task-based instruction", Computer Assisted Language Learning, 23(5), pp. 44-456.

De Higes, I. (en prensa). «Ignoring the Other: The exclusion of interpreters in the Spanish dubbing of It's a Free World...", Norwich Papers, I8.

De Marco, M. (20I2). Audiovisual Translation through a Gender Lens. Ámsterdam y Nueva York: Rodopi.

Delabastita, D. (1989). "Translation and mass-communication», Babel, 35 (4), pp. 193-218.

Delabastita, D. (I990). "Translation and the Mass Media». En Bassnett, S. y Lefevere, A. (eds.). Translation, History and Culture. London/Nueva York: Pinter, pp. 97-Io9.

Delabastita, D. (1996). «Introduction», The Translator, Wordplay and Translation: Essays on Punning and Translation, 2 (2), pp. I27-I39.
Díaz Cintas, J. (2003). Teoría y práctica de la subtitulación. Inglés-español. Barcelona: Ariel Cine.

Díaz Cintas, J. y Remael, A. (2007). Audiovisual Translation: Subtitling. Manchester: St. Jerome.

Díaz Cintas J. (2008a). "Audiovisual translation comes of age». En Chiaro, D., Heiss, C. y Bucaria, C. (eds.). Between Text and Image: Updating Research in Screen Translation. Ámsterdam y Filadelfia: Benjamins, pp. I-9.

Díaz Cintas, J. (ed.) (2008b). The Didactics of Audiovisual Translation. Ámsterdam y Filadelfia: Benjamins.

Dries, J. (1995). Dubbing and Subtitling Guidelines for Production and Distribution. Düsseldorf: EIM.

Espasa, E. (2002) - «Traducir documentales: Paisajes híbridos». En Sanderson, J. (ed.). Traductores para todo. Actas de las II Jornadas de Doblaje y Subtitulación. Alicante: Publicacions de la Universitat d'Alacant, pp. 29-29.

Espasa, E. (2008). «Big Brother is watching you: Diseño de audiencia y traducción audiovisual». En Sanderson, J. (ed.). Películas antiguas, subtitulos nuevos. Alicante: Publicacions de la Universitat d'Alacant, pp. 69-8o.

Franco, E. (2000). «Documentary film translation: A specific practice?». En Chesterman, A., Gallardo, N. y Gambier, Y. (eds.). Translation in Context. Ámsterdam y Filadelfia: Benjamins, pp. 233-24I.

Fodor, I. (1976). Film Dubbing: Phonetic, Semiotic, Esthetic and Psychological Aspects. Hamburgo: Helmut Buske.

Freddi, M. y Pavesi, M. (2009). Analysing audiovisual dialogue. Linguistic and translational insights. Bolonia: Clueb.

Fuentes, A. (1997-98). «La traducción de los títulos de películas y series de televisión», Sendebar, 8(9), pp. IO7-II4.

Fuentes, A. (2005). «La recepción de la traducción audiovisual: Humor y cultura». En Zabalbeascoa, P. Santamaría, L. y Chaume, F. (eds.). La traducción audiovisual: Investigación, enseñanza y profesión. Granada: Comares, pp. I39-I52.

Gambier, Y. (1998). Translating for the Media. Turku: Universidad de Turku.

Gambier, Y. y Suomela-Salmi, E. (1994). «Subtitling: A Type of Transfer». En Eguíluz, F., Merino, R., Olsen, V., Pajares, E. y Santamaría, J.M. (eds.). Trasvases Culturales: Literatura, Cine, Traducción. Vitoria: Universidad del País Vasco, pp. 243-252. 
Gambier, Y. y Gottlieb, H. (eds.) (200I). (Multi) Media Translation. Ámsterdam y Filadelfia: Benjamins.

Gautier, G.L. (1981). «La traduction au cinéma: nécessité et trahison», La revue du cinéma 363, pp. IOI-II8.

Ghia, E. (2012). Subtitling Matters. Berna: Peter Lang. Gómez Capuz, J. (I998). El préstamo lingüístico (conceptos, problemas y métodos). Valencia: Universitat de València.

González, V. (2005). «Traducción e ideología en el ámbito de los medios audiovisuales: El caso de los títulos cinematográficos» En Zabalbeascoa, P. Santamaría, L. y Chaume, F. (eds.). La traducción audiovisual: Investigación, enseñanza y profesión. Granada: Comares, pp. I27-I38.

Goris, O. (1993). «The Question of French Dubbing: Towards a Frame for Systematic Investigation», Target, 5 (2), pp. I69-I9o.

Gottlieb, H. (I997). Subtitles, Translation and Idioms. Copenhague: Universidad de Copenhague.

Gottlieb, H. (200I). «Anglicisms and TV Subtitles in an Anglified World». En Gambier, Y. y Gottlieb, H. (eds.). (Multi) Media Translation. Âmsterdam y Filadelfia: Benjamins, pp. 249-258.

Granell, X. (20II). «Teaching Video Game Localisation in Audiovisual Translation courses at university", Jostrans, I6, pp. 185-202.

Gutiérrez Lanza, C. (2000). «Proteccionismo y censura durante la etapa franquista: Cine nacional, cine traducido y control estatal». En Rabadán, R. (ed.). Traducción y censura inglés-español: 1939-1985. León: Universidad de León, pp. $23-59$.

Gutiérrez Lanza, C. (2005). «EDT basados en corpus textuales informatizados: perfeccionamiento metodológico en TRACEci». En Zabalbeascoa, P. Santamaría, L. y Chaume, F. (eds.). La traducción audiovisual: Investigación, enseñanza y profesión. Granada: Comares, pp. 87-98.

Heiss, C. (2004). «Dubbing Multilingual Films: A New Challenge?», Meta, 49 (I), pp. 208-220.

Hendrickx, P. (I984). «Partial dubbing», Meta, 29 (2), pp. 217-218.

Herbst, T. (1994). Linguistische Aspekte der Synchronisation von Fernsehserien. Phonetik, Textlinguistik, Übersetzungstheorie. Tubingen: Niemeyer.

Hochel, B. (I986). "Communicative aspects of translation for TV», Nouvelles de la FIT, 5 (3), pp. I5I-I57.
Hurtado, A. (20or). Traducción y Traductología. Madrid: Cátedra.

Hurtado de Mendoza, I. (2009). «Translating proper names into Spanish: The case of Forrest Gump». En Díaz Cintas, J. (ed.). New Trends in Audiovisual Translation. Bristol, Buffalo, Toronto: Multilingual Matters, pp. 70-82.

Ivarsson, J. (2002). «Subtitling through the Ages. A Technical History of Subtitles in Europe», Language International, I4(2), pp. 6-Io.

Izard, N. (I992). La traducció cinematogràfica. Barcelona: Publicacions de la Generalitat de Catalunya.

Izard, N. (200I). «Doblaje y subtitulación: Una aproximación histórica». En Duro, M. (ed.). La traducción para el doblaje y la subtitulación. Madrid: Cátedra, pp. 189-208.

Izard, N. (2004). "Versemblança i oralitat en la traducció audiovisual» [en línea], Quaderns Divulgatius, 24, <http://www.escriptors. cat/?q=publicacions_quadernsdivulgatius24_versemblanca>, [Consulta: 30 oct. 20I2].

Karamitrouglou, F. (2000). Towards a Methodology for the Investigation of Norms in Audiovisual Translation. Ámsterdam: Rodopi.

Laks, S. (I957). Le sous-titrage des films. Sa technique. Son esthétique. París: Manuscrito inédito.

Lambert, J. y van Gorp, H. (I985). «On Describing Translations». En Hermans, T. (ed.). The Manipulation of Literature. Nueva York: St Martin's Press, pp. 42-53.

Luyken, G.M. (I99I). Overcoming Linguistic Barriers in Television. Dubbing and Subtitling for the European Audience. Manchester: EIM.

Marleau, L. (I982). «Les sous-titres... un mal nécessaire», Meta, 27 (3), pp. 27I-285.

Martí Ferriol, J.L. (2010). Cine independiente y traducción. Valencia: Tirant lo Blanch.

Martínez Sierra, J.J. (2008). Humor y traducción. Los Simpson cruzan la frontera. Castellón de la Plana: Publicacions de la Universitat Jaume I.

Martínez Sierra, J.J. (20I2a). Introducción a la traducción audiovisual. Murcia: Universidad de Murcia, Editum.

Martínez Sierra, J.J. (20I2b). «On the relevance of script writing basics in audiovisual translation practice and training», Cadernos de Traduçao, 29, pp. $145-163$.

Martínez Sierra J.J., Martí Ferriol, J.L., de Higes Andino, I., Prats, A. y Chaume, F. (2010) «Lin- 
guistic Diversity in Spanish Immigration Films. A Translational Approach». En Berger, V., Ille, K. y Komori, M. (eds.). Polyglot Cinema: Migration and Transcultural Narration in France, Italy, Portugal and Spain. Viena: LIT.

Marzà, A. (2009). «La traducció audiovisual de l'animació a RTVV», Quaderns divulgatius, 36, Barcelona: Associació d'Escriptors en Llengua Catalana, pp. $3 \mathrm{3}^{-} 48$.

Marzà, A., Chaume, F., Torralba, G. y Alemany, A. (2006). «The language we watch: An approach to the linguistic model of Catalan in dubbing», Mercator Media Forum, 9. University of Wales, Aberystwyth, pp. I4-25.

Marzà, A. y Chaume, F. (2009). «The language of dubbing: present facts and future perspectives». En Freddi, M. y Pavesi, M. (eds.). Analysing audiovisual dialogue. Linguistic and translational insights. Bolonia: Clueb, pp. 31-40.

Mason, I. (I989). «Speaker meaning and reader meaning: preserving coherence in screen translating». En Kölmel, R. y Payne, J. (eds.). Babel. The Cultural and Linguistic Barriers between Nations. Aberdeen: Aberdeen University Press, pp. I3-24.

Mason, I. (200I). "Coherence in subtitling: The negotiation of face» En R. Agost y Chaume, F. (eds.). La traducción en los medios audiovisuales. Castellón de la Plana: Publicacions de la Universitat Jaume I, pp. I9-3I.

Matamala, A. (2009). «Interjections in original and dubbed sitcoms in Catalan: A comparison», Meta. 54 (3), pp. 485-502.

Mayoral, R., Kelly, D. y Gallardo, N. (I986). «Concepto de traducción subordinada (cómic, cine, canción, publicidad). Perspectivas no lingüísticas de la traducción (I). En Fernández, F. (ed.). Pasado, presente y futuro de la lingüistica aplicada en España. Actas del III Congreso Nacional de Lingüistica Aplicada. Valencia: Universitat de València, pp. 95-I05.

Mayoral, R., Kelly, D. y Gallardo, N. (I988) «Concept of Constrained Translation. Non-Linguistic Perspectives of Translation», Meta, 33 (3), pp. 356-367.

Mayoral, R. (200I). «El espectador y la traducción audiovisual» En R. Agost y Chaume, F. (eds.). La traducción en los medios audiovisuales. Castellón de la Plana: Publicacions de la Universitat Jaume I, pp. $33^{-} 46$.
Mubenga, K. S. (2009). "Towards a Multimodal Pragmatic Analysis of Film Discourse in Audiovisual Translation», Meta, 54 (3), pp. 466-484.

Neves, J. (2005). Audiovisual Translation: Subtitling for the Deaf and the Hard of Hearing. Tesis doctoral inédita.

Nord, C. (I990). «Funcionalismo y lealtad: algunas consideraciones en torno a la traducción de títulos». En Raders, M. y Conesa, J. (eds.). II Encuentros Complutenses en torno a la traducción. Madrid: Editorial Complutense, pp. I53-I62.

Nord, C. (1995). "Text-Functions in Translation: Titles and Headings as a case in Point», Target, 7(2), pp. 26I-284.

Paolinelli, M. y di Fortunato, E. (2005). Tradurre per il doppiaggio. Milán: Hoepli.

Pavesi, M. (2005). La traduzione filmica. Aspetti del parlato doppiato dall'inglese all'italiano. Roma: Carocci.

Pereira, A, y Lorenzo, L. (2005). «Notting Hill: Una traducción audiovisual como herramienta para la enseñanza de técnicas generals de la traducción». En Zabalbeascoa, P., Santamaría, L. y Chaume, F. (eds.). La traducción audiovisual: Investigación, enseñanza y profesión. Granada: Comares, pp. 24I-249.

Pérez-González, L. (2007). «Appraising Dubbed Conversation: Systemic Functional Insights into the Construal of Naturalness in Translated Film Dialogue», The Translator I3 (I), pp. I-38.

Pommier, C. (I988). Doublage et postsyncronisation. París: Dujarric.

Quaglio, P. (2009). Television Dialogue: The Sitcom Friends vs. Natural Conversation. Ámsterdam y Filadelfia: Benjamins.

Rabadán, R. (I99I). Equivalencia y traducción. León: Universidad de León.

Rabadán, R. (2000). Traducción y censura inglés-español: 1939-1985. León: Universidad de León.

Remael, A. (2004). «A place for film dialogue analysis in subtitling courses». En Orero, P. (ed.). Topics in Audiovisual Translation. Ámsterdam y Filadelfia: Benjamins, pp. 103-126.

Reiss, K. (I976). Texttyp und Übersetzungsmethode. Der Operative Text. Kronberg: Skriptor Verlag.

Richart, M. (2009). La alegría de transformar. Teorias de la traducción y teoría del doblaje audiovisual. Valencia: Tirant lo Blanch.

Romero Fresco, P. (2006). «The Spanish dubbese. 


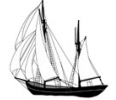

A case of (un)idiomatic Friends», Jostrans, 6, pp. I34-I5I.

Romero Ramos, M. G. (2010). Un estudio descriptivo sobre la traducción de la variación lingüistica en los medios audiovisuales (doblaje y subtitulación). Las traducciones de Il Postino. Tesis doctoral inédita.

Sanderson, J. (2009). «Strategies for the dubbing of puns with one visual semantic layer». En Díaz Cintas, J. (ed.). New Trends in Audiovisual Translation. Bristol, Buffalo, Toronto: Multilingual Matters, pp. I23-I32.

Santamaría, L. (200I). "Culture and translation. The referential and expressive value of cultural references». En R. Agost y Chaume, F. (eds.). La traducción en los medios audiovisuales. Castellón de la Plana: Publicacions de la Universitat Jaume I, pp. I59-I64.

Santaemilia, J. y B. Soler (20I0). «Els títols dels films de Quentin Tarantino: una perspectiva multilingüe», Quaderns, I7, pp. I67-I82.

Snell-Hornby, M. (1988). Translation Studies. Ámsterdam y Filadelfia: Benjamins.

Spadafora, A. (2007). Intermedia. La mediazione linguistica negli audiovisivi. Vitterbo: Sette Città.

Soh-Tatcha, C. (2009). "Doublage cinématographique et audiovisual: équivalence de son, équivalence de sens», Meta, 54 (3), pp. 503-519.

Sokoli, S. (2005). «Temas de investigación en traducción audiovisual: La definición del texto audiovisual» En Zabalbeascoa, P. Santamaría, L. y Chaume, F. (eds.). La traducción audiovisual: Investigación, enseñanza y profesión. Granada: Comares, pp. I77-185.

Talaván, N. (2009). Aplicaciones de la traducción audiovisual para mejorar la comprensión oral del inglés. Tesis doctoral inédita.

Titford, C. (I982). «Sub-titling: constrained translation». Lebende Sprachen, 27(3), pp. II3-ı16.

Tveit, J.E. (2009). «Dubbing vs. subtitling: Old battleground revisited» En Díaz Cintas, J. y Anderman, G. (eds.). Audiovisual Translation. Language Transfer on Screen. Basingstoke: Palgrave Macmillan, pp. 85-96.

Valdeón, R. (2005). «Asymmetric representations of languages in contact: uses and translations of French and Spanish in Frasien. En Delabastita, D. y Grutman, R. (eds.). Fictionalising Translation and Multilingualism, Linguistica Antverpiensia, 4, pp. 279-294.
Valentini, C. (2006). «A multimedia database for the training of audiovisual translators», Jostrans, 6, pp. 68-84.

Vöge, H. (1977). «The translation of films, subtitling versus dubbing», Babel, 23(3), pp. I2O-I25.

Von Flotow, L. (2009). «Frenching the feature film twice. Or le synchronien au débat». En Díaz Cintas, J. (ed.). New Trends in Audiovisual Translation. Bristol, Buffalo, Toronto: Multilingual Matters, pp. 83-98.

Whitman-Linsen, C. (1992). Through the Dubbing Glass. Frankfurt am Main: Peter Lang.

Zabalbeascoa, P. (1993). Developing Translation Studies to Better Account for Audiovisual Texts and Other New Forms of Text Production. Tesis doctoral inédita.

Zabalbeascoa, P. (1996). «In Search of a Model that will work for the Dubbing of Television Comedy». En Edo, M. (1996). Actes del I Congrés Internacional sobre Traducció i Interpretació. Barcelona: UAB, pp. 350-366.

Zabalbeascoa, P. (I997). "La didáctica de la traducción: Desarrollo de la competencia traductora». En Gil de Carrasco, A. y Hickey, L. (eds.). Aproximaciones a la traducción. Madrid: Instituto Cervantes, pp. 22-40.

Zabalbeascoa, P. (2000). «From techniques to types of solutions». En Beeby, A., Ensinger, D. y Presas, M. (eds.). Investigating Translation. Ámsterdam y Filadelfia: Benjamins, pp. II7-I27.

Zabalbeascoa, P. (200I). «La ambición y la subjetividad de una traducción desde un modelo de prioridades y restricciones». En Sánchez Trigo, E. y Díaz Fouces, Ó. (eds.). Traducción E̊ Comunicación. Vigo: Servicio de Publicacións, pp. I29-I5O.

Zabalbeascoa, P., Santamaría, L. y Chaume F. (eds.) (2005). La traducción audiovisual: Investigación, enseñanza y profesión. Granada: Comares.

Zanettin, F. (I998). «Fumetti e traduzione multimediale» [en línea]. Intralinea, rivista di traduttologia, vol. I. <http://www.intralinea.org/archive/ article/Fumetti_e_traduzione_multimediale >, [Consulta: 30 oct. 20I2].

Zanettin, F. (2008). Comics in Translation. Manchester: St. Jerome.

Zaro, J.J. (200I). «Conceptos traductológicos para el análisis del doblaje y la subtitulación». En Duro, M. (ed.). La traducción para el doblaje y la subtitulación. Madrid: Cátedra, pp. 47-63. 